\title{
Analisis Beban Kerja Untuk Mengetahui Jumlah Pekerja Optimal Karyawan Dengan Menggunakan Metode Work Load Analysis Di PT. Surya Toto Indonesia, Tbk
}

\section{Workload Analysis To Optimizing Total Man Power At PT. Surya Toto Indonesia, Tbk}

\author{
${ }^{1 .}$ Ossa Sutaarga, ${ }^{2 \cdot}$ M. Ramlan \\ 1,2. Program Studi Teknik Industri, Fakultas Teknik, Universitas Muhammadiyah Tangerang \\ 1.ossa.sutaarga@gmail.com, 2.mramlan@gmail.com
}

\begin{abstract}
This research is focused on increasing productivity by optimizing total manpower in the HR field related to work activities and time needed by employees to complete their tasks in accordance with the Job Description given by management. The method used in this research is Work Load Analysis which is a picture of the workload needed in an organization in a company. With this method can provide information about the allocation of employee resources in completing workloads. PT. Surya Toto Indonesia is always trying to improve the quality of its products and services. If there is no particular attention to quality or productivity, the company will decline. The average productivity obtained from the measurement of productivity rose by $10 \%$, with a test of the adequacy of the data $N=164$, the level of accuracy of the data $S=6.2 \%$, the level of confidence of the data of $=95 \%$.
\end{abstract}

Keywords: Workload Analysis, Human Resource Management.

\begin{abstract}
ABSTRAK
Penelitian ini difokuskan pada peningkatkan produktivitas dengan mengoptimalkan total manpower pada bidang SDM berkaitan dengan aktivitas kerja dan waktu yang dibutuhkan karyawan untuk menyelesaikan tugas - tugasnya sesuai dengan Job Description yang diberikan oleh pihak manajemen. Metode yang digunakan dalam penelitian ini yaitu Work Load Analysis yang merupakan gambaran dari beban kerja yang dibutuhkan dalam suatu organisasi pada suatu perusahaan. Dengan metode ini dapat memberikan informasi mengenai pengalokasian sumber daya karyawan dalam menyelesaikan beban kerjanya. PT. Surya Toto Indonesia selalu berusaha ingin meningkatkan kualitas produk maupun jasanya. Apabila tidak ada perhatian yang khusus terhadap kualitas maupun produktivitas maka perusahaan tersebut akan menurun. Rata-rata produktivitas yang didapat dari pengukuran produktivitas naik $10 \%$, dengan uji kecukupan data $\mathrm{N}=164$, tingkat ketelitian data $\mathrm{S}=6.2 \%$, tingkat kepercayaan data sebesar $=95 \%$.
\end{abstract}

Kata Kunci : Analisa Beban Kerja, Manajemen Sumber Daya Manusia.

\section{PENDAHULUAN}

PT. Surya Toto Indonesia selalu berusaha ingin meningkatkan kualitas produk maupun jasanya. Apabila tidak ada perhatian yang khusus terhadap kualitas maupun produktivitas maka perusahaan tersebut akan menurun jumlah permintaan / order. Agar lebih berkualitas dan produktif maka harus dengan peningkatan efektifitas dan efisiensi. Permasalahan yang dihadapi perusahaan adalah peningkatan efesiensi yaitu penentuan jumlah pekerja yang optimal berdasarkan produktivitas pada Departemen Polishing 3 dengan metode Work Load Analysis.

Terima 04 - February - 2020, Revisi 03 - Maret - 2020, Disetujui 15 - Agustus - 2020 
Peningkatkan efisiensi pada bidang Sumber Daya Manusia. Efisiensi dalam bidang SDM berkaitan dengan aktivitas kerja dan waktu yang dibutuhkan karyawan untuk menyelesaikan tugas - tugasnya sesuai dengan Job Description yang diberikan oleh pihak manajemen. Metode yang digunakan dalam penelitian ini yaitu Work Load Analysis yang merupakan gambaran dari beban kerja yang dibutuhkan dalam suatu organisasi pada suatu perusahaan. Dengan metode ini dapat memberikan informasi mengenai pengalokasian sumber daya karyawan dalam menyelesaikan beban kerjanya.

Berdasarkan latar belakang diatas maka diperoleh rumusan masalah sebagai berikut, Bagaimana cara meningkatkan presentase produktivitas pada bagian polishing 3, Berapakah jumlah pekerja optimal karyawan polishing 3.

Tujuan yang ingin dicapai pada penelitian ini adalah sebagai berikut, Mengetahui presentase produktivitas karyawan Polishing 3 sesuai dengan waktu observasi, Mengetahui jumlah karyawan yang optimal pada polishing 3.

\section{METODE PENELITIAN}

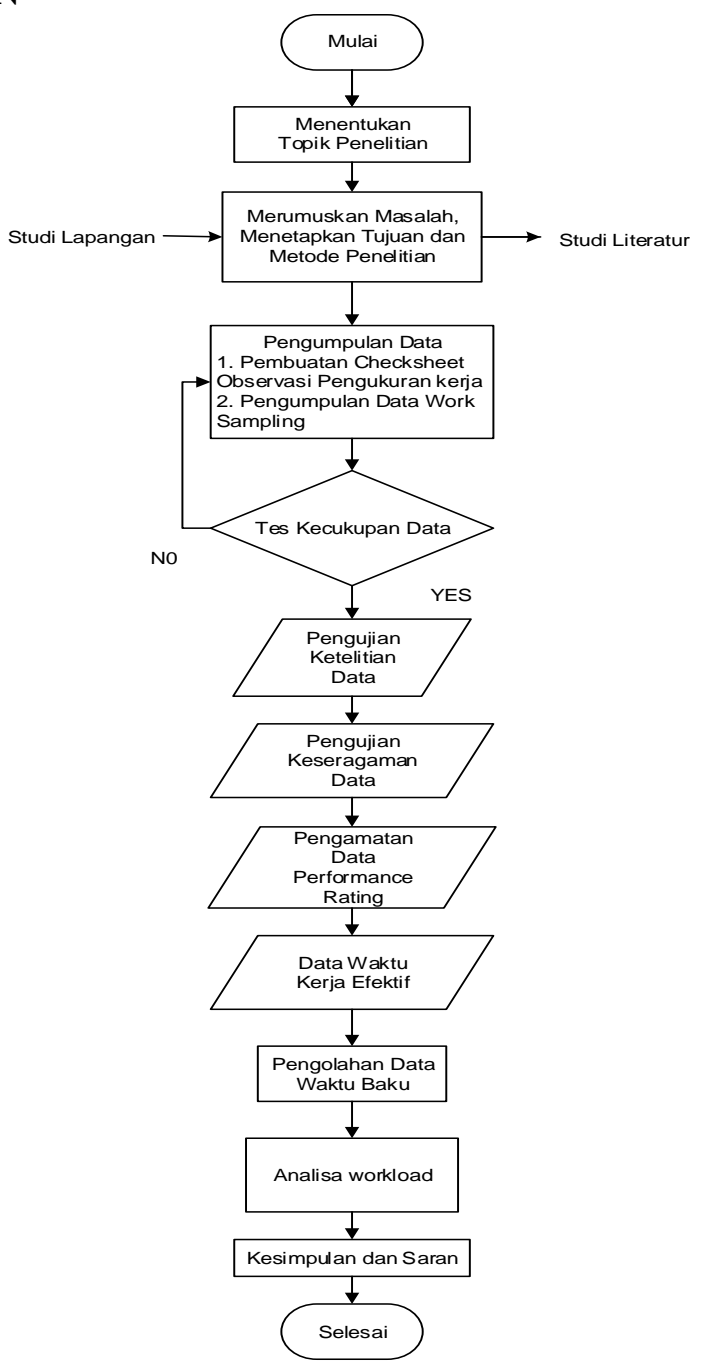

Gambar 1. Flowchart Metode Penelitian

Penelitian dilakukan selama 1 bulan terhitung dari tanggal 01 Juli sampai 31 Juli 2019. Penelitian dilakukan pada hari kerja dan jam kerja, hari kerja senin-jumat pukul 08.000-17.00

JIM, Vol. 5, No. 2, Agustus 2020, pp.1 - 10 
WIB. Data yang diambil pada penelitian ini adalah data dari bagian polishing 3 dimana sampel yang digunakan dalam penelitian ini berjumlah 10 orang.

Dalam teknik pengumpulan data, peneliti memperoleh data sebagai bahan penelitian dengan menggunakan data primer dan data sekunder sebagai berikut.

a. Data Primer

Data primer diperoleh dengan cara melakukan observasi langsung di lapangan yaitu dengan

melakukan pengukuran terhadap kinerja karyawan yaitu data jam kerja aktual karyawan.

b. Data sekunder

Data sekunder diperoleh dari studi literature, baik dari tulisan, referensi yang relevan, jurnal - jurnal yang berkaitan, data dari perusahaan maupun sumber-sumber lain yang menunjang penelitian.

Dalam pengambilan data pengukuran kerja digunakan metode work sampling yang dilakukan secara self observation pada seluruh operator. Data yang telah diambil maka dibuatkan analisis data yang dilakukan dengan menggunakan alat bantu Work Sampling guna mempermudah dalam penghitungan metode Work Load Analysis untuk mengetahui tingkat efisiensi kerja berdasarkan total presentasi beban kerja dari job yang diberikan dalam menyelesaikan pekerjaannya.

Sebagai tahapan pre-study maka pengambilan data sampel kerja dilakukan selama 4 hari kerja dengan melibatkan 4 orang operator yang berbeda tiap harinya. Pencatatan hasil pengamatan menggunakan checksheet yang berisi macam-macam aktivitas atau kegiatan dari operator pemindahan unit baik yang bersifat produktif.

Tabel 1. Contoh Rekap Hasil Pre-Study Sampel Kerja

\begin{tabular}{|c|c|c|c|c|c|}
\hline Observasi Hari ke & D-1 & $\mathrm{D}-2$ & D-3 & D-4 & \multirow{2}{*}{ Total } \\
\hline Nama Operator & Roni & Mamat & Dodi & Adri & \\
\hline Total kegiatan produktif teramati & 21 & 20 & 23 & 24 & 88 \\
\hline Total kegiatan non produktif teramati & 9 & 10 & 7 & 6 & 32 \\
\hline Total pengamatan per hari & 30 & 30 & 30 & 30 & 120 \\
\hline Total pemindahan unit mobil / hari & 64 & 65 & 69 & 72 & 270 \\
\hline & & & & & Rata2 \\
\hline$\%$ kegiatan produktif & $70 \%$ & $66.67 \%$ & $76.67 \%$ & $80.00 \%$ & $73.33 \%$ \\
\hline \% kegiatan non produktif & $30 \%$ & $33.33 \%$ & $23.33 \%$ & $20.00 \%$ & $26.67 \%$ \\
\hline
\end{tabular}

Sumber : PT. Surya TOTO (2011)

Setelah hasil pre-study sampel kerja didapatkan maka salah satu tahapan pengukuran kerja yang harus dilakukan adalah melakukan tes kecukupan data untuk mengetahui apakah data pengamatan sudah cukup mewakili seluruh populasi atau belum.

Dimana,

$\mathrm{S}$ : Tingkat ketelitian yang dikehendaki dan dinyatakan dalam desimal

$\mathrm{P}$ : Total presentase produktif dibagi jumlah pengamatan dan dinyatakan dalam bentuk desimal

$\mathrm{N}$ : Jumlah minimum pengamatan yang harus dilakukan untuk sampel kerja

$\mathrm{K}$ : Harga indeks yang besarnya tergantung dari tingkat kepercayaan yang diambil.

$$
\mathrm{N}^{\prime}=\frac{K^{2}(1-P)}{S^{2} P}
$$

Setelah pengujian kecukupan data maka peneliti melakukan pengujian tingkat ketelitian data, yang mana ini dimaksudkan untuk mengetahui seberapa besar tingkat ketelitiannya (degree of accuracy) dari seluruh data pengukuran kerja yang sudah didapatkan sebelumnya.

$$
\mathrm{S}=\mathrm{k} \frac{\sqrt{P(1-P)}}{N}
$$


Lalu peneliti akan menguji keseragaman data yang dimaksudkan untuk mengidentifikasi adanya data ekstrim, yaitu data terlalu besar atau data terlalu kecil dari tren rata-ratanya. Peneliti menggunakan Batas Kendali Atas dan Batas Kendali Bawah untuk menguji keseragaman data. Jika ternyata terdapat data yang menyimpang dari standar maka data tersebut harus dibuang atau tidak diikutkan ke dalam pengolahan data yang telah diambil sebelumnya.

$\mathrm{BKA}=\mathrm{P}+3 \sqrt{\frac{P(1-P)}{N}}$

$\mathrm{BKB}=\mathrm{P}-3 \sqrt{\frac{P(1-P)}{N}}$

Dalam penelitian ini peneliti akan mengevaluasi nilai performance rating didapatkan dari hasil pengisian pengamatan checksheet yang mengacu pada tabel Westing House System Rating oleh seorang foreman yang telah berpengalaman beberapa tahun dalam memimpin operator polishing. Tabel 2.2 menunjukan rekap hasil data pengamatan performance rating. Dari tabel 2.2 dapat dilihat bahwa nilai rata-rata evaluasi untuk seluruh operator polishing menurut Westing House System's Rating adalah sebesar 0,86. Dalam pengambilan data ini peneliti juga menghitung waktu kerja efektif menggunakan data sekunder berupa kalender kerja. Dari data kalender kerja tersebut maka selanjutnya dapat dilakukan perhitungan jumlah hari kerja efektif pada yang ditunjukan pada tabel 2.3

Tabel 2. Contoh Rekap Hasil Evaluasi Penilaian Performance Rating

\begin{tabular}{|c|c|c|c|c|c|c|c|}
\hline \multirow{4}{*}{\multicolumn{2}{|c|}{ Klasifikasi }} & \multirow{4}{*}{\multicolumn{2}{|c|}{ Rating }} & \multicolumn{4}{|c|}{ Nama Operator } \\
\hline & & & & Tatang & Rahmat & Yahya & Agil \\
\hline & & & & \multicolumn{4}{|c|}{ Observasi } \\
\hline & & & & Hari ke 1 & Hari ke 2 & Hari ke 3 & Hari ke 4 \\
\hline \multirow{11}{*}{ 恋 } & \multirow{2}{*}{ Super skill } & A1 & 0.15 & & & & \\
\hline & & A2 & 0.13 & & & & \\
\hline & \multirow{2}{*}{ Excellent } & B1 & 0.11 & . & & . & \\
\hline & & B2 & 0.08 & & . & & . \\
\hline & \multirow{2}{*}{ Good } & C1 & 0.06 & & & & \\
\hline & & C2 & 0.03 & & & & \\
\hline & Average & D & $\mathbf{0}$ & & & & \\
\hline & \multirow{2}{*}{ Fair } & E1 & -0.05 & & & & \\
\hline & & E2 & -0.1 & & & & \\
\hline & \multirow{2}{*}{ Poor } & F1 & -0.16 & & & & \\
\hline & & F2 & -0.22 & & & & \\
\hline \multirow{11}{*}{ 莺 } & \multirow{2}{*}{ Excessive } & A1 & 0.13 & & & & \\
\hline & & A2 & 0.12 & & & & \\
\hline & \multirow{2}{*}{ Excellent } & B1 & 0.1 & & & & \\
\hline & & B2 & 0.08 & & . & & \\
\hline & \multirow{2}{*}{ Good } & C1 & 0.05 & & & & \\
\hline & & C2 & 0.02 & . & & & \\
\hline & Average & D & $\mathbf{0}$ & & & . & . \\
\hline & \multirow{2}{*}{ Fair } & E1 & -0.04 & & & & \\
\hline & & E2 & -0.08 & & & & \\
\hline & \multirow{2}{*}{ Poor } & $\mathbf{F 1}$ & -0.12 & & & & \\
\hline & & F2 & -0.17 & & & & \\
\hline \multirow{6}{*}{ 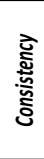 } & Ideal & A & 0.04 & & & & \\
\hline & Excellent & B & 0.03 & & & & \\
\hline & Good & C & 0.01 & & . & & . \\
\hline & Average & D & $\mathbf{0}$ & . & & . & \\
\hline & Fair & $\mathbf{E}$ & -0.02 & & & & \\
\hline & Poor & $\mathbf{F}$ & -0.04 & & & & \\
\hline \multirow{6}{*}{ 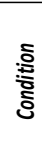 } & Ideal & A & 0.06 & & & & \\
\hline & Excellent & B & 0.04 & . & & . & \\
\hline & Good & C & 0.02 & & . & & \\
\hline & Average & D & $\mathbf{o}$ & & & & . \\
\hline & Fair & $\mathbf{E}$ & -0.03 & & & & \\
\hline & Poor & $\mathbf{F}$ & -0.07 & & & & \\
\hline & & & Total & 0.17 & 0.19 & 0.15 & 0.09 \\
\hline & & & Rata2 & \multicolumn{4}{|c|}{0.15} \\
\hline
\end{tabular}

Sumber : PT. Surya TOTO

JIM, Vol. 5, No. 2, Agustus 2020, pp.1 - 10 
Tabel 3. Jumlah Hari Kerja Efektif

\begin{tabular}{|l|c|}
\hline \multicolumn{1}{|c|}{ Keterangan } & Jumlah hari \\
\hline Jumlah hari dalam setahun & 365 hari \\
\hline Jumlah hari cuti bersama & 4 hari \\
\hline Jumlah hari cuti individu & 8 hari \\
\hline Jumlah libur nasional & 11 hari \\
\hline Jumlah hari sabtu dan minggu & 122 hari \\
\hline Jumlah hari kerja Efektif & 220 hari \\
\hline
\end{tabular}

Sumber : PT. Surya TOTO

Ketika data sudah didapatkan maka peniliti mengolah data tersebut. Pada tahap pengolahan data ini akan dilakukan untuk menentukan besarnya waktu baku dari operator polishing berdasarkan data-data pengukuran kerja ( work sampling) yang sudah didapatkan sebelumnya. Dalam hal ini penentuan besarnya waktu baku dilakukan karena dari pihak manajemen logistik sendiri tidak pernah memberikan standar resmi berkaitan dengan waktu baku proses yang terjadi pada saat pengiriman barang.

Sehingga perhitungan waktu baku dari operator polishing akan menjadi seperti rumus berikut ini :

Dimana,

Wn : Waktu normal yang dibutuhkan untuk menyelesaikan per unit produk

$\mathrm{Wb}$ : Waktu baku / standar yang dibutuhkan untuk menyelesaikan per unit produk

$\mathrm{P} \quad$ : Persentase produktif rata-rata yang dinyatakan dalam bentuk angka desimal

Tn : Total waktu pengamatan

Pf : Faktor penyesuaian / Performance rating (\%)

$\mathrm{Np} \quad$ : Jumlah unit produk yang dihasilkan selama masa pengamatan

A : Faktor kelonggaran / allowance (\%)

$$
\begin{gathered}
\mathrm{Wn}=\frac{\operatorname{Tn} \times \mathrm{P} \times \mathrm{Pf}}{\mathrm{Np}} \\
\mathrm{Wb}=\mathrm{Wn} \times \frac{100 \%}{100 \%-\text { allowance }}
\end{gathered}
$$

Metode analisa data dalam penelitian ini adalah sebagai berikut Pada tahapan terakhir dari penelitian ini akan dilakukan analisis perhitungan jumlah pekerja optimal untuk proses kerja pada bagian polishing berikut ini adalah data-data utama yang diperlukan untuk melakukan jumlah pekerja optimal :

1. Data penting yang harus didapatkan untuk melakukan analisa perhitungan ini yaitu berapa jumlah unit penerimaan barang yang harus diproses oleh operator polishing selama tahun 2012. Dalam penelitian ini data yang digunakan adalah data sekunder berupa data penerimaan barang pada tahun sebelumnya alasan digunakannya data ini yaitu berdasarkan asumsi bahwa penerimaan barang yang terdapat ditahun 2011 adalah sebanyak 13987 pcs. Untuk selanjutnya data ini akan dinotasikan dengan symbol "p".

2. Waktu baku proses penerimaan oleh operator yang didapatkan dari pengukuran kerja secara langsung menggunakan pengolahan data work sampling adalah sebesar 7.89 menit. Untuk selanjutnya data ini akan dinotasikan dengan symbol "Wb".

3. Jumlah menit kerja efektif yang tersedia bagi operator polishing yang didapatkan dari data kalender kerja perusahaan yaitu akan dinotasikan dengan symbol " $D$ "

4. Data terakhir yang diperlukan yaitu faktor efisiensi kerja yang ditetapkan oleh perusahaan kepada seluruh karyawan / pegawainya. Besarnya faktor efisiensi yang ditetapkan oleh perusahaan ini idealnya adalah sebesar $80 \%$ ( tingkat persentase produktifitas yang diinginkan perusahaan). Untuk selanjutnya data ini dinotasikan dengan symbol "E" 
Setelah keempat data diatas diperoleh maka dengan menggunakan rumus perhitungan jumlah operator optimal akan dihasilkan nilai seperti berikut.

$$
\mathrm{N}=\frac{P \times W b}{D \times E(79 \%)}
$$

\section{HASIL DAN PEMBAHASAN}

\section{Pengumpulan data}

Tabel 4. Pengumpulan Data

\begin{tabular}{|c|c|c|c|}
\hline No & Activitas & $\begin{array}{c}\text { Jumlah } \\
\text { aktivitas }\end{array}$ & $\begin{array}{c}\text { Total pengamatan } \\
\text { 10 hari }\end{array}$ \\
\hline 1 & Produktif & 149 & 210 \\
\hline 2 & Tidak Produktif & 31 & 210 \\
\hline 3 & Kelonggaran waktu & 30 & 210 \\
\hline
\end{tabular}

Nilai produktif $=\frac{149}{210}=0,7099$ atau $70.99 \%$

Nilai non produktif $\quad=\frac{31}{210}=0,1476$ atau $14.76 \%$

Nilai kelonggaran $\quad=\frac{30}{210}=0.1428$ atau $14.28 \%$

\section{Kecukupan data}

Dari hasil pre-study sampel kerja didapatkan bahwa persentase kegiatan produktif ratarata yang teramati yaitu sebesar $71 \%$. Dengan menggunakan tingkat kepercayaan sebesar $95 \%$ (harga indeks $\mathrm{k}=2$ ) dan tingkat ketelitian sebesar $10 \%$ maka jumlah sampel pengamatan yang harus diambil yaitu :

$$
\begin{aligned}
& \mathrm{N}^{\prime}=\frac{K^{2}(1-P)}{S^{2} P} \\
& \mathrm{~N}^{\prime}=\frac{2^{2}(1-0,709)}{0,1^{2} \times 0,709} \\
& \mathrm{~N}^{\prime}=\frac{4(0,291)}{0,01 \times 0,709} \\
& \mathrm{~N}^{\prime}=\frac{1164}{0,00709} \\
& \mathrm{~N}=164 \text { Minimum data pengamatan }
\end{aligned}
$$

Dari hasil perhitungan diatas dapat diamati bahwa N: $210>\mathrm{N}$ : 164 sehingga dapat diasumsikan bahwa data pengamatan sampel kerja dianggap sudah cukup.

\section{Ketelitian Data}

Tingkat ketelitian data peneliti menggunakan 10\% derajat ketelitian yang telah ditetapkan sebelumnya.

$$
\begin{aligned}
\mathrm{S} & =\mathrm{k} \frac{\sqrt{P(1-P)}}{N} \\
& =2 \frac{\sqrt{0.709(1-0.709)}}{210} \\
& =2 \frac{\sqrt{0.2063}}{210} \\
& =2 \sqrt{0.00098} \\
& =2(0.031) \\
& =0.062 \text { atau } 6,2 \%
\end{aligned}
$$

JIM, Vol. 5, No. 2, Agustus 2020, pp.1 - 10 
Karena dalam penelitian ini harga $S=6,2 \%$ adalah lebih kecil dari $10 \%$ (derajat ketelitian yang ditetapkan pada batasan masalah) maka jumlah pengamatan acak yang sudah dilakukan sebanyak 210 kali akan cukup memenuhi syarat ketelitian yang ditetapkan.

\section{Keseragaman Data}

Pada penelitian ini batas kontrol diambil untuk tingkat kepercayaan sebesar 95\% sehingga harga $\mathrm{k}=2$ dan tingkat produktivitas yang didapatkan dari hasil sampel kerja sebesar $71 \%$. Berdasarkan data rata-rata persentase waktu produktif yang sudah didapatkan maka akan diperoleh hasil perhitungan sebagai berikut. Rata-rata presentase kegiatan produktif :

$\mathrm{P}=0,709$

BKA dan BKB

$$
\begin{aligned}
\mathrm{BKA} & =\mathrm{P}+3 \sqrt{\frac{P(1-P)}{N}} \\
& =0,709+3 \sqrt{\frac{0,709(1-0,709)}{210}} \\
& =0,709+3 \sqrt{\frac{0,206}{210}} \\
& =0,709+3 \sqrt{0,0009} 8 \\
& =0,709+3(0,031) \\
& =0,709+0,093 \\
& =0,802
\end{aligned}
$$

\begin{tabular}{|c|c|c|c|c|}
\hline Operator & Data & BKA & BKB & Rata - rata \\
\hline Faizal & 0.666 & \multirow{10}{*}{0.802} & \multirow{10}{*}{0.616} & \multirow{10}{*}{0.709} \\
\hline Abay & 0.619 & & & \\
\hline Rizky & 0.761 & & & \\
\hline Yudi & 0.761 & & & \\
\hline Lutfi & 0.761 & & & \\
\hline Repian & 0.714 & & & \\
\hline Rahmat & 0.666 & & & \\
\hline Udin & 0.714 & & & \\
\hline Eko & 0.761 & & & \\
\hline Endar & 0.666 & & & \\
\hline
\end{tabular}

$$
\begin{aligned}
\mathrm{BKB} & =\mathrm{P}-3 \sqrt{\frac{P(1-P)}{N}} \\
& =0,709-3 \sqrt{\frac{0,709(1-0,709)}{210}} \\
& =0,709-3 \sqrt{\frac{0,206}{210}} \\
& =0,709-3 \sqrt{0,0009} 8 \\
& =0,709-3(0,031) \\
& =0,709-0,093 \\
& =0,61
\end{aligned}
$$

Tabel 5. Hasil Perhitungan Batas Kontrol

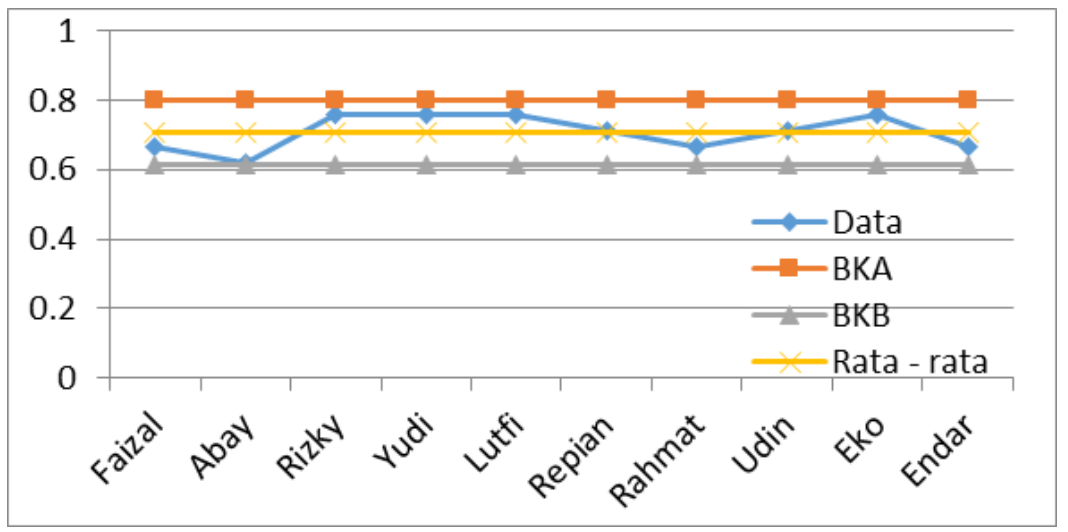

Gambar 2. Chart BKA BKB 
Dari gambar tersebut dapat dilihat bahwa dari 5 hari pengamatan tidak ditemukan data yang menyimpang dari batas kontrol atas maupun bawah.

\section{Performance Rating}

Dalam penelitian ini data evaluasi nilai performance rating didapatkan dari hasil pengisian pengamatan checksheet yang mengacu pada tabel Westing House System Rating oleh seorang foreman yang telah berpengalaman beberapa tahun dalam memimpin operator polishing.

Tabel 6. Performance Rating

\begin{tabular}{|c|c|c|c|c|c|c|c|c|c|c|c|c|c|}
\hline \multirow{4}{*}{\multicolumn{2}{|c|}{ Klasifikasi }} & \multirow{4}{*}{\multicolumn{2}{|c|}{ Rating }} & \multicolumn{10}{|c|}{ Nama Operator } \\
\hline & & & & Faisal & Abay & Rizky & Yudi & Lutfi & Repian & Rahmat & Udin & Eko & Endar \\
\hline & & & & \multicolumn{10}{|c|}{ Observasi } \\
\hline & & & & \multicolumn{2}{|c|}{ Hari ke 1} & \multicolumn{2}{|c|}{ Hari ke 2} & \multicolumn{2}{|c|}{ Hari ke 3} & \multicolumn{2}{|c|}{ Hari ke 4} & \multicolumn{2}{|c|}{ Hari ke 5} \\
\hline \multirow{11}{*}{ ज } & \multirow{2}{*}{ Super skill } & A1 & 0.15 & & & & & & & & & & \\
\hline & & A2 & 0.13 & & & & & & & & & & \\
\hline & \multirow{2}{*}{ Excellent } & B1 & 0.11 & . & & & & & & & & . & . \\
\hline & & B2 & 0.08 & & . & & . & & & . & . & & \\
\hline & \multirow{2}{*}{ Good } & C1 & 0.06 & & & & & . & . & & & & \\
\hline & & $\mathrm{C2}$ & 0.03 & & & & & & & & & & \\
\hline & Average & D & 0 & & & & & & & & & & \\
\hline & \multirow{2}{*}{ Fair } & E1 & -0.05 & & & & & & & & & & \\
\hline & & E2 & -0.1 & & & & & & & & & & \\
\hline & \multirow{2}{*}{ Poor } & F1 & -0.16 & & & & & & & & & & \\
\hline & & F2 & -0.22 & & & & & & & & & & \\
\hline \multirow{11}{*}{ 茍 } & \multirow{2}{*}{ Excessive } & A1 & 0.13 & & & & & & & & & & \\
\hline & & A2 & 0.12 & & & & & & & & & & \\
\hline & \multirow{2}{*}{ Excellent } & B1 & 0.1 & & & & & & & & & & \\
\hline & & B2 & 0.08 & & . & & & & & & & & \\
\hline & \multirow{2}{*}{ Good } & C1 & 0.05 & & & & & & . & & . & & \\
\hline & & C2 & 0.02 & . & & & & . & & . & & . & . \\
\hline & Average & D & 0 & & & . & . & & & & & & \\
\hline & \multirow{2}{*}{ Fair } & E1 & -0.04 & & & & & & & & & & \\
\hline & & E2 & $\mid-0.08$ & & & & & & & & & & \\
\hline & \multirow{2}{*}{ Poor } & F1 & -0.12 & & & & & & & & & & \\
\hline & & F2 & -0.17 & & & & & & & & & & \\
\hline \multirow{6}{*}{ 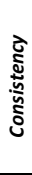 } & Ideal & A & 0.04 & & & & & & & . & & & \\
\hline & Excellent & B & 0.03 & & & & & & . & & & & \\
\hline & Good & C & 0.01 & & . & & . & & & & . & & . \\
\hline & Average & D & 0 & . & & . & & & & & & . & \\
\hline & Fair & $E$ & -0.02 & & & & & & & & & & \\
\hline & Poor & $\mathbf{F}$ & -0.04 & & & & & & & & & & \\
\hline & Ideal & A & 0.06 & & & & & & & & & & \\
\hline & Excellent & B & 0.04 & . & & . & & & & & & & \\
\hline$\stackrel{0}{:}$ & Good & $\mathrm{C}$ & 0.02 & & . & & & . & & & & . & \\
\hline కั & Average & D & 0 & & & & . & & . & & . & & . \\
\hline & Fair & $E$ & -0.03 & & & & & & & . & & & \\
\hline & Poor & $\mathbf{F}$ & -0.07 & & & & & & & & & & \\
\hline & $0=(1-0.14)=$ & & Total & 0.17 & 0.19 & 0.15 & 0.09 & 0.1 & 0.13 & 0.14 & 0.14 & 0.15 & 0.14 \\
\hline & $=(1-0.14)=$ & & Rata2 & & & & & & & & & & \\
\hline
\end{tabular}

Dari tabel 3.2 dapat dilihat bahwa nilai rata-rata evaluasi untuk seluruh operator polishing menurut Westing House System 's Rating adalah sebesar 0,86.

\section{Pengolahan Data}

Wn : Waktu normal yang dibutuhkan untuk menyelesaikan per unit produk

$\mathrm{Wb}$ : Waktu baku / standar yang dibutuhkan untuk menyelesaikan per unit produk

$\mathrm{P}$ : Persentase produktif rata-rata yang dinyatakan dalam bentuk angka desimal

Tn : Total waktu pengamatan

Pf : Faktor penyesuaian / Performance rating (\%)

$\mathrm{Np}$ : Jumlah unit produk yang dihasilkan selama masa pengamatan

a : Faktor kelonggaran / allowance (\%) 


$$
\begin{aligned}
\mathrm{Wn} & =\frac{\operatorname{Tn} \times \mathrm{P} \times \mathrm{Pf}}{\mathrm{Np}} \\
& =\frac{2.100 \times 0,709 \times 0,86}{110} \\
& =\frac{1.280,454}{110} \\
& =11,64
\end{aligned}
$$

$$
\begin{aligned}
\mathrm{Wb} & =\mathrm{Wn} \times \frac{100 \%}{100 \%-\text { allowance }} \\
& =11,64 \times \frac{1}{1-0,14} \\
& =11,64 \times \frac{1}{0,86} \\
& =11,64 \times 1,1628 \\
& =13,53
\end{aligned}
$$

Dari hasil perhitungan di atas dapat diketahui bahwa waktu baku yang diperlukan oleh operator polishing untuk melakukan suatu proses pengiriman barang sampai dengan semua persyaratan diselesaikan adalah selama 13,53 menit.

\section{Analisa data}

Pada tahapan terakhir dari penelitian ini akan dilakukan analisis perhitungan jumlah pekerja optimal untuk proses kerja pada bagian polishing berikut ini adalah data-data utama yang diperlukan untuk melakukan jumlah pekerja optimal :

$$
\begin{aligned}
\mathrm{N} & =\frac{P \times W b}{D \times E(79 \%)} \\
& =\frac{65.232 \times 13,53}{126.360 \times 0,79} \\
& =\frac{882.588,96}{99.824,4} \\
& =8,84 \text { atau di ekuivalenkan menjadi } 9 \text { orang }
\end{aligned}
$$

Perhitungan analisis beban kerja didapatkan jumlah pekerja optimal adalah sebanyak 9 orang. Dengan mengoptimalkan jumlah pekerja maka otomatis akan berdampak pada penurunan biaya operasional untuk proses kerja polishing.

\section{KESIMPULAN DAN SARAN Kesimpulan}

Dari hasil dan pembahasan diatas maka dapat ditarik kesimpulan bahwa PT. Surya TOTO dapat meningkatkan presentase produktivitas dengan cara mengoptimalkan total manpower yang ada. Dimana PT. Surya TOTO harus menghitung Waktu Baku yang berjalan saat ini dengan mengkategorikan 3 aktivitas yaitu Productive, Unproductive, Allowance. Dari ketiga kategori tersebut maka kegiatan unproductive yang harus di kurangi atau bisa dihilangkan.

Setelah hal tersebut dilakukan maka PT. Surya TOTO bisa mendapatkan hasil total manpower efektif dimana total manpower sebelumnya terdapat 10 orang di bagian polishing, setelah pengoptimalan manpower maka menjadi 9 manpower. Untuk 1 manpower yang dikurangi dapat dialokasikan ke posisi department yang lain, maka total presentase optimal manpower dapat dimaksimalkan menjadi $10 \%$.

\section{Saran}

Saran yang diberikan oleh penulis adalah PT. Surya TOTO harus sustain dan konsisten dalam menjalankan optimalisasi penggunaan manpower. Yang mana hal ini dapat memberikan dampak positif bagi perusahaan. Setelah perhitungan dibagian polishing di sarankan PT. Surya TOTO juga bisa menghitung bagian yang lain agar menambah Produktivitas perusahaan.

Dengan meningkatnya produktifitas dalam pengoptimalan manpower sebaiknya PT. Surya TOTO juga menghitung cost terhadap dampak meningkatnya produktifitas perusahaan. Hal ini bertujuan agar pihak Top Management dapat melihat dampak dari pengoptimalan manpower dengan menggunalan WLA (Work Load Analysis). 


\section{DAFTAR PUSTAKA}

Ajitia N, M. G., \& Prasetya, A. (2017). Efektivitas Manpower Planning Dengan Menggunakan Metode Analisis Beban Kerja (Work Load Analysis) Berdasarkan Pendekatan Full TIME Equivalent (Studi Pada Divisi Pengembangan Karir, Organisasi, Dan Kompetensi Di PT. Pupuk Kalimantan Timur Tbk. Bontang, Ka. Jurnal Administrasi Bisnis, 42(1), 27-35.

Anggraeni, L. E., \& Prabowo, R. (2015). Analisis Beban Kerja untuk Menentukan Jumlah Karyawan Optimal (Studi Kasus: PT. Sanjayatama Lestari Sirabaya). Institut Teknologi Adhi Tama Surabaya. Surabaya.

Eko, W., \& Sabeni, A. (2012). Analisis value added sebagai indikator intellectual capital dan konsekuensinya terhadap kinerja perbankan (Doctoral dissertation, Fakultas Ekonomika dan Bisnis).

Gomez, M. E., \& Santonja, V. (1998, November). Self-similarity in I/O workload: analysis and modeling. In Workload Characterization: Methodology and Case Studies. Based on the First Workshop on Workload Characterization (pp. 97-104). IEEE.

Medernach, E. (2005, June). Workload analysis of a cluster in a grid environment. In Workshop on Job Scheduling Strategies for Parallel Processing (pp. 36-61). Springer, Berlin, Heidelberg.

Singgih, M. L., \& Dewita, E. (2008). Analisis Beban Kerja Karyawan Pada Departemen Umum Dan Logistik Dengan Metode Work Load Analysis Di Perusahaan Percetakan. In Prosiding Seminar Nasional Teknoin.

Wibowo, F. D. (2006). Analisis Pengaruh Peran Kepemimpinan dan Pengembangan Karir Terhadap Komitmen Organisasi Dalam Meningkatkan Kinerja Karyawan (Studi Kasus: PT. Bank Maspion Indonesia Cabang Semarang) (Doctoral dissertation, program Pascasarjana Universitas Diponegoro). 